\title{
Mathematical modelling of oxygen transport-limited follicle growth
}

\author{
G P Redding ${ }^{1}$, J E Bronlund ${ }^{1}$ and A L Hart ${ }^{2}$ \\ ${ }^{1}$ Institute of Technology and Engineering, Massey University, Private Bag 11222, Palmerston North 4410, New \\ Zealand ${ }^{2}$ Food and Health, AgResearch Grasslands, Private Bag 11008, Palmerston North 4410, New Zealand \\ Correspondence should be addressed to G P Redding; Email: g.p.redding@massey.ac.nz
}

\begin{abstract}
Mathematical modelling was used to investigate oxygen transport in the developing ovarian follicle. In contrast to previous findings, the results show that oxygen can reach the oocyte in large preantral follicles. This is largely due to the inclusion of fluid voidage in the model and improved estimates of oxygen diffusion coefficients through the granulosa. The results also demonstrate that preantral follicles will eventually reach a size beyond which further growth will result in the follicle becoming increasingly anoxic. The predicted size range at which this occurs is consistent with the size range at which antrum formation is observed in many mammals. This suggests that the antrum formation stage of follicular growth may be pivotal to the further development and ultimate fate of the follicle, and that antrum formation itself may represent a mechanism by which the follicle can overcome oxygen limitations. This was supported through extension of the model to the antral follicle, which showed that antrum formation can provide a way in which the follicle can continue to grow and yet avoid becoming hypoxic. The results of the model were consistent with observed follicle development.
\end{abstract}

Reproduction (2007) 133 1095-1106

\section{Introduction}

It is generally accepted that oxygen supply is of importance to the developing ovarian follicle. However, a quantitative understanding of nutrient supply in the follicle is generally lacking (Clark et al. 2006).

Despite the lack of quantitative information, it has been suggested that as the follicle grows, the thickening granulosa layer will not receive an adequate supply of oxygen, and that this may play an important role in granulosa cell death and follicle atresia (Hirshfield 1991). It has been further speculated that antrum formation may be one way in which a lack of oxygen supply can be overcome (Gosden \& Byatt-Smith 1986), and that intrafollicular oxygen levels may rise as a result of antrum formation (Van Blerkom 1998).

The level of follicular vascularity (Van Blerkom et al. 1997, Chui et al. 1997, Bhal et al. 1999, Huey et al. 1999, Kim et al. 2004) and dissolved oxygen in follicular fluid (Van Blerkom et al. 1997) have been related to the developmental competence of the oocyte and/or in-vitro fertilisation (IVF) outcome, but these parameters are difficult to measure. The reliable measurement of dissolved oxygen levels in follicular fluid requires attention to the avoidance of preanalytical errors (Redding et al. 2006).
Owing to the difficulties associated with the measurement of oxygen, mathematical modelling is particularly suited to gaining an improved understanding of the role this nutrient plays in the developing follicle. This approach was employed by Gosden \& Byatt-Smith (1986) to show that oxygen does not reach the oocyte in the preantral follicle. This leads to the speculation that the metabolism of the early oocyte may be anaerobic. More recently, Clark et al. (2006) modelled oxygen transport across the cumulus-oocyte complex and demonstrated that the cumulus cells consume little oxygen, thus sparing it for the oocyte. The same authors also suggest that the results of Gosden \& Byatt-Smith (1986) should be reviewed as the latter's results were based on the use of an underestimated diffusion coefficient through the granulosa cells.

The objectives of this work were to use mathematical modelling of oxygen transport in the preantral follicle to determine whether oxygen can reach the oocyte, and in the antral follicle to determine whether antrum formation and subsequent follicle growth may be mechanisms consistent with overcoming oxygen limitations. The model proposed by Gosden \& Byatt-Smith (1986) was revisited to obtain an improved understanding of oxygen transport in the preantral follicle. This model was then 
extended to describe oxygen transport in the antral follicle, so that the effect of antrum formation could be determined.

\section{Materials and Methods}

\section{Conceptual model development and assumptions}

Figure 1 depicts the preantral and antral follicles side by side with their geometric model representations. The preantral follicle is assumed to consist of an approximately spherical sack of granulosa cells. Since little is known about oocyte metabolism during the early stages of follicle development, the oocyte is assumed to have the same properties as the granulosa layer, and hence is not explicitly included in the model. It is seen to be sufficient to make an inference as to whether or not oxygen reaches the area which the oocyte would occupy. This assumption is the same as that made by Gosden \& Byatt-Smith (1986). The follicle is assumed to be completely surrounded by vascularisation at an oxygen concentration equal to that of arterial plasma. Mass transport is assumed to be by diffusion through the granulosa layer that consumes oxygen at a constant rate. The assumption of constant oxygen consumption of the granulosa cells has been shown to have an insignificant effect on the oxygen concentration profiles through the follicle compared with when oxygen consumption rate varies as a function of concentration (Redding 2007). This occurs because the oxygen consumption rate of granulosa cells has been shown to fall from an essentially constant value only at very low oxygen concentrations (Gosden \& Byatt-Smith 1986). Therefore, where the current model predicts oxygen concentrations of zero, a model that incorporates, for example, MichaelisMenton kinetics predicts a very low concentration slightly above zero. Thus, the inclusion of such kinetics is seen as providing little useful information relative to the objectives of this work and would unnecessarily complicate the model.

In the human preantral follicle, the oocyte radius increases from $\sim 12.5$ to $40 \mu \mathrm{m}$ (Peters \& McNatty 1980). Simultaneously, the follicle grows, with the follicle radius increasing from $25 \mu \mathrm{m}$ (Peters \& McNatty 1980) to $200 \mu \mathrm{m}$ (McNatty 1978), the size at which the formation of the fluid-filled antrum is observed. During this phase of growth, increasing fluid voids are observed in the spaces between granulosa cells (Fig. 1). Therefore, the granulosa cells may be assumed to be tightly packed in the small preantral follicle, with fluid voidage $(\varepsilon)$ increasing as the preantral follicle grows. Fluid voidage is defined in this work as the volume fraction of the granulosa layer occupied by fluid spaces between granulosa cells. The inclusion of fluid voidage was not considered by Gosden \& Byatt-Smith (1986). Fluid voids make oxygen transport easier as there is no oxygen consumption in the fluid voids. Furthermore, if diffusion of oxygen is more rapid through the fluid spaces than through cells, the inclusion of fluid voidage in the granulosa layer will make oxygen transport easier through an increased effective diffusion coefficient through this layer.

When the follicle radius reaches $\sim 200 \mu \mathrm{m}$ in humans, the formation of the fluid-filled antrum is observed. The antrum is the product of the increasing volume of fluid collecting in a common region and may initially be the result of a reduction in the fluid voidage in the granulosa layer and a coalescence of ejected fluid into the central antrum. The resulting antral follicle continues to grow (as both granulosa and fluid volumes increase), reaching a radius of $\sim 8 \mathrm{~mm}$ (McNatty 1981). The formation of the antrum results in the granulosa layer forming an exterior shell, with the granulosa/antrum interface located some distance from the follicle centre. In the antral model, the

\section{FOLLICLE DEVELOPMENT MODEL APPROXIMATION}
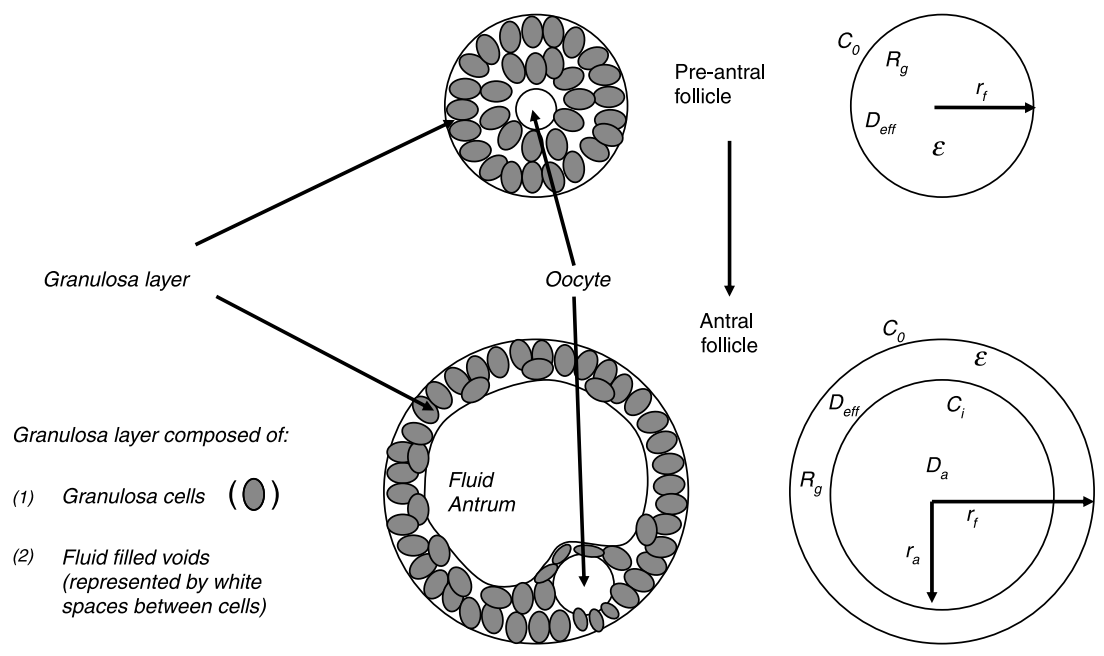

Figure 1 Model approximation of follicle development. 
oocyte is not explicitly included, but assumed to reside within the granulosa layer just touching the granulosa/ antrum interface. This assumption has negligible impact on model predictions due to the comparatively small volume occupied by the oocyte/cumulus-oocyte complex. Upon diffusion through the granulosa layer, oxygen will reach the fluid where there is no oxygen consumption. Therefore, the oxygen levels across the fluid will be constant, and the fluid may serve the function of oxygen/nutrient storage.

The next stage of follicle development is the preovulatory follicle. In this phase, the oocyte is suspended by a stalk of granulosa cells (the cumulus oophorus), and may be located in a more central position. However, in large mammals, such as humans, the large volume of the fluid antrum results in the cumulus-oocyte complex being more likely to be in an eccentric position near the granulosa layer (Mossman \& Duke 1973). Therefore, in large mammals, the antral model proposed in this work will also be a fair representation of the preovulatory follicle.

\section{Mathematical model}

Equations describing oxygen transport in the follicle can be derived via a steady-state oxygen balance over the follicle ( $0=$ oxygen in - oxygen out - oxygen consumed).

$0=\frac{D_{\text {eff }}}{r^{2}} \frac{\mathrm{d}}{\mathrm{d} r}\left(r^{2} \frac{\mathrm{d} C}{\mathrm{~d} r}\right)-R_{\mathrm{g}}(1-\varepsilon)$

The derivation of the equation that predicts the steadystate oxygen concentration across the preantral follicle has previously been described by Gosden \& Byatt-Smith (1986). The equation modified by the inclusion of fluid voidage $(\varepsilon)$ is

$C=C_{\mathrm{o}}-\frac{R_{\mathrm{g}}(1-\varepsilon)}{6 D_{\text {eff }}}\left(r_{\mathrm{f}}^{2}-r^{2}\right) \quad$ for $\quad 0 \leq r \leq r_{\mathrm{f}}$

If $C<0$, then $C=0$ (concentration cannot be negative), where

$C$ is the concentration of oxygen at any position $r$ in the follicle

$C_{\mathrm{o}}$ is the concentration of oxygen at the follicle surface

$R_{\mathrm{g}}$ is the rate of oxygen consumption per unit volume of granulosa cells

$\varepsilon$ is the volume fraction of the granulosa layer occupied by fluid

$D_{\text {eff }}$ is the diffusion coefficient of oxygen through the granulosa layer

$r_{f}$ is the radius of the follicle

$r$ is the radial distance from the follicle centre

Equation (2) differs from that of Gosden \& Byatt-Smith (1986) in the inclusion of fluid voidage (Fig. 1), which accounts for the fact that there is no oxygen consumption in these fluid spaces between granulosa cells. The inclusion of fluid voidage also impacts on the value of the effective diffusion coefficient of oxygen in the granulosa layer $\left(D_{\text {eff }}\right)$, when it is assumed to be composed of both fluid voids and cells (the calculation of $D_{\text {eff }}$ is detailed in the parameter estimation section). Gosden \& Byatt-Smith (1986) assumed the granulosa cell layer to be composed entirely of cells. This assumption may be fair when the follicle is small and the cells are tightly packed, as in the small preantral follicle; however, it is unlikely to be true as the follicle grows and fluid voids are observed.

Equation (2) can be used to calculate the critical follicle radius $\left(r_{\text {fcrit }}\right)$ above which oxygen cannot reach the oocyte surface, by setting Eq. (2) equal to zero at $r=r_{\mathrm{o}}$ and solving for $r_{\mathrm{f}}$. The equation is

$r_{\text {fcrit }}=\sqrt{r_{\mathrm{o}}^{2}+\frac{6 D_{\text {eff }} C_{\mathrm{o}}}{R_{\mathrm{g}}(1-\varepsilon)}}$

where

$$
\begin{aligned}
& r_{\text {fcrit }} \text { is the critical follicle radius beyond which } \\
& \text { oxygen will no longer reach the oocyte } \\
& \text { surface in the preantral follicle } \\
& r_{\mathrm{O}} \text { is the radius of the oocyte. }
\end{aligned}
$$

For the antral follicle model, it is assumed that the fluid space is symmetrically surrounded by granulosa cells, and that there is no oxygen consumption within the fluid space. Therefore, at steady state, the oxygen concentration in the fluid will be uniform throughout and equal to the oxygen concentration at the granulosa/antrum interface. Thus, the equation describing the oxygen concentration at any position $r$ in the antral fluid is

$C=C_{\mathrm{i}}$ for $0 \leq r \leq r_{\mathrm{a}}$

where

$C_{\mathrm{i}}$ is the oxygen concentration at the granulosa/ antrum interface

$r_{\mathrm{a}}$ is the distance from the follicle centre to the granulosa/antrum interface.

By application of the appropriate boundary conditions ( $\mathrm{d} C / \mathrm{d} r=0$ at $r=r_{\mathrm{a}}$ and $C=C_{\mathrm{o}}$ at $r=r_{\mathrm{f}}$ ), Eq. (1) can also be solved analytically (see Redding (2007) for full derivation) to give an equation that describes the oxygen concentration at any position $r$ in the granulosa layer of the antral follicle,

$$
C=C_{\mathrm{o}}-\frac{R_{\mathrm{g}}(1-\varepsilon)}{6 D_{\text {eff }}}\left(r_{\mathrm{f}}^{2}-r^{2}\right)-\frac{R_{\mathrm{g}}(1-\varepsilon) r_{\mathrm{a}}^{3}}{3 D_{\text {eff }}}\left(\frac{1}{r_{\mathrm{f}}}-\frac{1}{r}\right)
$$

for $r_{\mathrm{a}} \leq r \leq r_{\mathrm{f}}$ 
By setting $C=C_{\mathrm{i}}$ at $r=r_{\mathrm{a}}$ in Eq. (5), the following equation is obtained:

$C_{\mathrm{i}}=C_{\mathrm{o}}-\frac{R_{\mathrm{g}}(1-\varepsilon)}{6 D_{\mathrm{eff}}}\left(r_{\mathrm{f}}^{2}-r_{\mathrm{a}}^{2}\right)-\frac{R_{\mathrm{g}}(1-\varepsilon) r_{\mathrm{a}}^{3}}{3 D_{\text {eff }}}\left(\frac{1}{r_{\mathrm{f}}}-\frac{1}{r_{\mathrm{a}}}\right)$

Equation (6) can be used to calculate the concentration of oxygen at the granulosa/antrum interface.

Alternatively, for any given follicle volume (known $\left.r_{\mathrm{f}}\right)$, this equation can be used to solve for the radius, $r_{\mathrm{a}}$, of the antrum at which the oxygen concentration will fall to a certain level $\left(C_{\mathrm{i}}\right)$ at the granulosa/antrum interface.

In this case, a practically feasible solution for $r_{\mathrm{a}}$ only exists if the follicle radius is large enough to ensure $C \leq C_{\mathrm{i}}$ at some point in the follicle. For the antral follicle, this condition will always be met, provided the oxygen concentration in a preantral follicle of the same size is $\leq C_{\mathrm{i}}$ at the follicle centre. Thus, by setting $C=C_{\mathrm{i}}$ and $r=$ 0 in Eq. (2), the additional condition of solution for $r_{\mathrm{a}}$ in Eq. (6) can be calculated as

$r_{\mathrm{f}} \geq \sqrt{\frac{6\left(C_{\mathrm{o}}-C_{\mathrm{i}}\right) D_{\text {eff }}}{R_{\mathrm{g}}(1-\varepsilon)}}$

Note that this condition needs only to be applied to Eq. (6) for the investigation of the relationship between some value of $C_{\mathrm{i}}$ and the size of the antrum $\left(r_{\mathrm{a}}\right)$. In this work, the situation of critical interest is defined as $C_{\mathrm{i}}=0$, i.e. the point at which oxygen will only just make it through the granulosa layer. All solutions of Eq. (6) considered in this work refer to this situation.

Eq. (6) is a cubic polynomial for $r_{\mathrm{a}}$ and can be solved analytically. MATLAB (Version 7.0, 2004, The MathWorks Inc., Natick, MA, USA) was used to find the root that lies in the practically feasible range, $0 \leq r_{\mathrm{a}}<r_{\mathrm{f}}$.

\section{Estimation of parameters}

Table 1 describes the symbols used in the model, as well as the estimates of parameter values. Nominal parameter values are given as a most likely estimate of the true values. Experimental data sources for a range of mammalian species were used due to the scarcity of specific reported values for these parameters. Therefore, a range over which each parameter might be reasonably expected to vary has also been estimated.

\section{Estimation of the oxygen concentration at the follicle surface $\left(C_{o}\right)$}

The partial pressure of oxygen in human maternal arterial blood has been reported by Fischer et al. (1992) as $102 \pm$ $3.4 \mathrm{mmHg}$ ( \pm s.D). The range used in this work is 95.2 $108.6 \mathrm{mmHg}$ ( \pm 2 s.D). To calculate the concentration of oxygen at the follicle surface, Henry's law can be used (concentration $=$ partial pressure $\times$ solubility). This requires knowledge of the solubility of oxygen in the follicle. In this work, the solubility of oxygen in the follicle is assumed to be constant throughout and equal to that of the follicular fluid. The relative solubility of oxygen in human follicular fluid to water has been reported as $0.91 \pm 0.02$ (Redding 2007). At $37^{\circ} \mathrm{C}$, the solubility of oxygen in water is $0.00137 \mathrm{mM} / \mathrm{mmHg}$ (Battino et al. 1983). Hence, the solubility of oxygen in human follicular fluid can be calculated as $0.00137 \times 0.91=$ $0.00125 \mathrm{mM} / \mathrm{mmHg}$ (nominal value) with a range of $0.00119-0.00130 \mathrm{mM} / \mathrm{mmHg}$ ( \pm 2 s.D). Therefore, according to Henry's law, the nominal oxygen concentration at the follicle surface will be $102 \times 0.00125=$ $0.1275 \mathrm{mM}$, with a range of $0.113-0.141 \mathrm{mM}$.

\section{Estimation of the oxygen consumption rate of the granulosa cells $\left(R_{g}\right)$}

The value for the oxygen consumption rate of the granulosa cells used was that reported by Gosden \& Byatt-Smith (1986) for the granulosa cells of sheep. This value is consistent with the oxygen consumption rates of human tissue (Fournier 1998, Truskey et al. 2004a). The value is $0.0363 \pm 0.0065 \mathrm{mM} / \mathrm{s}$ ( \pm s.D.) with a range of $0.0233-0.0493 \mathrm{mM} / \mathrm{s}( \pm 2 \mathrm{~s} . \mathrm{D})$. Once again, this range is intended to include the values expected for most mammalian species.

Estimation of the fluid voidage of the granulosa layer ( $(\varepsilon)$ The fluid voidage $(\varepsilon)$ of typical biological tissues ranges from 0.06 to 0.3 (Tai \& Chang 1974, Dutta \& Popel 1995, Nicholson 2001, Truskey et al. 2004b). Fluid voidage as

Table 1 Symbols and parameter estimates. Nominal values are considered to be best estimates, whilst the ranges listed are intended to include values that might be reasonably expected for most mammalian species.

\begin{tabular}{|c|c|c|c|c|c|}
\hline Symbol & Units & Description & $\begin{array}{l}\text { Nominal } \\
\text { value }\end{array}$ & Range & Reference \\
\hline$C_{\mathrm{o}}$ & $\mathrm{mM}$ & Oxygen concentration at follicle surface & 0.1275 & $0.113-0.141$ & Multiple (see text) \\
\hline$R_{\mathrm{g}}$ & $\mathrm{mM} \cdot \mathrm{s}^{-1}$ & Oxygen consumption rate of the granulosa cells & 0.0363 & $0.0233-0.0493$ & Gosden \& Byatt-Smith (1986) \\
\hline$\varepsilon$ & $\mathrm{n} / \mathrm{a}$ & Volume fraction of fluid in the granulosa layer & 0.3 & $\begin{array}{l}\text { Wide range tested } \\
\text { (see text) }\end{array}$ & Multiple (see text) \\
\hline$D_{\text {eff }}$ & $\mathrm{m}^{2} \cdot \mathrm{s}^{-1}$ & $\begin{array}{l}\text { Effective diffusion coefficient of oxygen in the } \\
\text { granulosa layer }\end{array}$ & $0.7 \times 10^{-9}$ & $\begin{array}{l}\text { Function of } \varepsilon \text { (i.e. } \\
\text { wide range tested) }\end{array}$ & Multiple (see text) \\
\hline$D_{\mathrm{a}}$ & $\mathrm{m}^{2} \cdot \mathrm{s}^{-1}$ & $\begin{array}{l}\text { Diffusion coefficient of oxygen in fluid voids and } \\
\text { follicular fluid }\end{array}$ & $2.6 \times 10^{-9}$ & $2.3-2.9 \times 10^{-9}$ & Redding (2007) \\
\hline
\end{tabular}


high as 0.6 has been observed in tumour tissue (Truskey et al. 2004b). For the preantral follicle, this work will examine the effect of a wide range of fluid voidages. As the follicle develops, the observed increase in fluid voidage in the granulosa layer suggests that the fluid voidage of this layer is likely to be at the higher end of values observed in biological tissues. For this reason, a nominal value of $\varepsilon=0.3$ has been used for the antral model. Although this is a reasonable estimate, studies quantifying fluid voidage in the granulosa layer of the developing follicle are recommended. Particularly, knowledge of the fluid voidage as a function of follicle size will not only reveal the magnitude of this parameter but also show any changes in this parameter as the follicle grows (e.g. the possible coalescence of fluid voids at antrum formation may result in a reduction in the fluid voidage of this layer after antrum formation). Such information will allow both more accurate predictions and a dynamic simulation of the transition from preantral to antral follicle. Species-specific fluid voidages are also estimated as part of this work (Table 2).

\section{Estimation of the diffusion coefficient of oxygen in the granulosa layer $\left(D_{\text {eff }}\right)$}

The diffusion coefficient of oxygen in the granulosa layer $\left(D_{\text {eff }}\right)$ can be described by combining the diffusion coefficients through the cellular and fluid parts of this layer into an overall effective diffusion coefficient $\left(D_{\text {eff }}\right)$. An empirical correlation that has been shown to be effective over a wide range of fluid voidages (Riley et al. 1994, 1995, 1996) was used to calculate $D_{\text {eff }}$ and is given by

$$
\begin{aligned}
\frac{D_{\text {eff }}}{D_{\mathrm{a}}}= & 1-\left(1-\frac{D_{\mathrm{g}}}{D_{\mathrm{a}}}\right)\left(1.727(1-\varepsilon)-0.8177(1-\varepsilon)^{2}\right. \\
& \left.+0.09075(1-\varepsilon)^{3}\right)
\end{aligned}
$$

where

$D_{\mathrm{a}}$ is the diffusion coefficient of oxygen in the fluid voids of the granulosa layer (assumed to be the same as that in the fluid-filled antrum)
$D_{\mathrm{g}}$ is the diffusion coefficient of oxygen through pure granulosa cells.

In this work, the diffusion coefficient of oxygen in the follicular fluid of the antrum $\left(D_{\mathrm{a}}\right)$ is assumed to be the same as that of the fluid voids in the granulosa layer. The diffusivity of oxygen through human follicular fluid relative to water has been reported as $0.86 \pm 0.05$ (Redding 2007), and this value is required to calculate the effective diffusion coefficient of oxygen through the granulosa layer. At $37^{\circ} \mathrm{C}$, Lango et al. (1996) gave a preferred value of oxygen diffusivity in water of $3.0 \times 10^{-9} \mathrm{~m}^{2} / \mathrm{s}$. Using this value, the oxygen diffusion coefficient in follicular fluid can be expressed in absolute terms at $37^{\circ} \mathrm{C}$ as $2.6 \pm 0.2 \times 10^{-9} \mathrm{~m}^{2} / \mathrm{s}( \pm$ S.D.), with a range of $2.3-2.9 \times 10^{-9} \mathrm{~m}^{2} / \mathrm{s}( \pm 2$ s.D). It should be noted that the parameter values in this work have been estimated at $37^{\circ} \mathrm{C}$. There is evidence that suggests that the temperature of some mammalian follicles may be lower than that of the surrounding tissue by as much as $2{ }^{\circ} \mathrm{C}$ (see Hunter et al. (2006) for summary). This will result in increased oxygen solubility in the follicle and reduced diffusion coefficients. It has been verified that this effect is minimal over such temperature ranges and, in any case, may be more relevant to follicles in the preovulatory phase.

Due to the variability in reported diffusion coefficients through tissues and cells, it is not possible to obtain a precise estimate of $D_{\mathrm{g}}$. By considering the available experimental information (Evans et al. 1981, Jones 1984, Jones \& Kennedy 1986, Rumsey et al. 1990, Lango et al. 1996), as well as theoretical determinations (Tai \& Chang 1974), a feasible range for the diffusion coefficient of oxygen in pure granulosa cells $\left(D_{\mathrm{g}}\right)$ is estimated to range from 1 to $5 \times 10^{-10} \mathrm{~m}^{2} / \mathrm{s}$. Therefore, the nominal value of $D_{\mathrm{g}}$ is taken as $3 \times 10^{-10} \mathrm{~m}^{2} / \mathrm{s}$ (mid range).

Since $D_{\mathrm{g}}$ is lower than $D_{\mathrm{a}}$, increasing the fluid voidage of the granulosa layer according to Eq. (7) will result in an increased effective diffusion coefficient through the granulosa layer. Note that according to this equation, as expected, if the fluid voidage is 0 , then $D_{\text {eff }}=D_{g}$, and if the fluid voidage is 1 , then $D_{\text {eff }}=D_{a}$.

Table 2 Oocyte radius, follicle radius at antrum formation and estimated granulosa layer fluid voidage at antrum formation for various species.

\begin{tabular}{lcclc}
\hline Species & Oocyte radius $(\mu \mathrm{m})$ & $\begin{array}{l}\text { Follicle radius when } \\
\text { antrum first appears }(\mu \mathrm{m})\end{array}$ & Reference & Estimated voidage \\
\hline Rat & 32 & 100 & Parkes $(1931)$ & 0.09 \\
Mouse & 35 & 100 & Parkes (1931) & 0.09 \\
Horse & 36 & 110 & Driancourt (1979) & 0.14 \\
Pig & 38 & 200 & Parkes (1931) & 0.46 \\
Human & 40 & 200 & McNatty (1978) and Peters \& McNatty (1980) \\
Baboon & 42 & 155 & Parkes (1931) & 0.46 \\
Rabbit & 42 & 125 & Parkes (1931) & 0.33 \\
Sheep & 47 & 150 & Turnbull et al. (1977) & 0.20 \\
Buffalo & 53 & 300 & Kumar et al. (1997) & 0.30 \\
Ferret & 54 & 115 & Parkes (1931) & 0.65 \\
Range & $32-54$ & $100-300$ & & 0.13 \\
\hline
\end{tabular}


At the nominal parameter estimates described, $D_{\text {eff }}$ is calculated to be $\sim 25 \%$ of the diffusion coefficient of oxygen in follicular fluid. This value is consistent with the argument of Clark et al. (2006), which suggests that the diffusion coefficients of oxygen in tissue are of an order of magnitude similar to that of the fluid phase. The same authors use a value for $D_{\text {eff }}$ in the cumulus-oocyte complex, which is essentially the same as that of water. This is likely a good assumption in the cumulus-oocyte complex, whose expanded nature will result in a high fluid voidage and therefore, according to Eq. (7), an effective diffusion coefficient, which approaches that of the fluid phase. This may not be the case for all tissues, including the more tightly packed granulosa layer. This is supported by a significant body of experimental evidence, which suggests that the effective diffusion coefficients of oxygen in biological tissue are of a similar order of magnitude, but lower than the fluid phase (Evans et al. 1981, Lango et al. 1996). Although some of these results may be too low due to failure to account for oxygen consumption in the tissue, even those results that do account for this (for example Evans et al. 1981) are still lower than that of the fluid phase. Ideally, experimental determinations of oxygen diffusivity in the granulosa layer are required to achieve a more accurate description of this parameter.

Estimation of follicle radius $\left(r_{f}\right)$ and oocyte radius at antrum formation $\left(r_{o}\right)$

The radius of the follicle was varied within ranges typical of preantral and antral follicles to investigate the relationship between follicular growth and oxygen transport. For humans, these ranges are 25 to $200 \mu \mathrm{m}$ (small to large preantral follicle) and 200 to $>8000 \mu \mathrm{m}$ (small to large antral follicle). The radii of the follicle and oocyte at antrum formation are of particular interest and are listed for various mammalian species in Table 2.

\section{Results}

Figure $2 a$ shows the oxygen concentration profiles predicted across a small preantral follicle using Eq. (2) and parameter estimates both favourable (best case) and unfavourable (worst case) to oxygen transport when fluid voidage is not considered (i.e. $\varepsilon=0$ and $D_{\text {eff }}=D_{\mathrm{g}}$ ). Parameter estimates favourable to oxygen transport refer to the combination of parameter estimates, which result in the greatest oxygenation of the follicle at any given size. These are high oxygen concentration at the follicle surface $\left(C_{\mathrm{o}}\right)$, low oxygen consumption rate of the granulosa cells $\left(R_{\mathrm{g}}\right)$ and a high effective diffusion coefficient of oxygen in the granulosa layer $\left(D_{\text {eff }}\right)$, where high and low refer to the upper and lower estimates of the range of each parameter determined in the parameter estimates section.
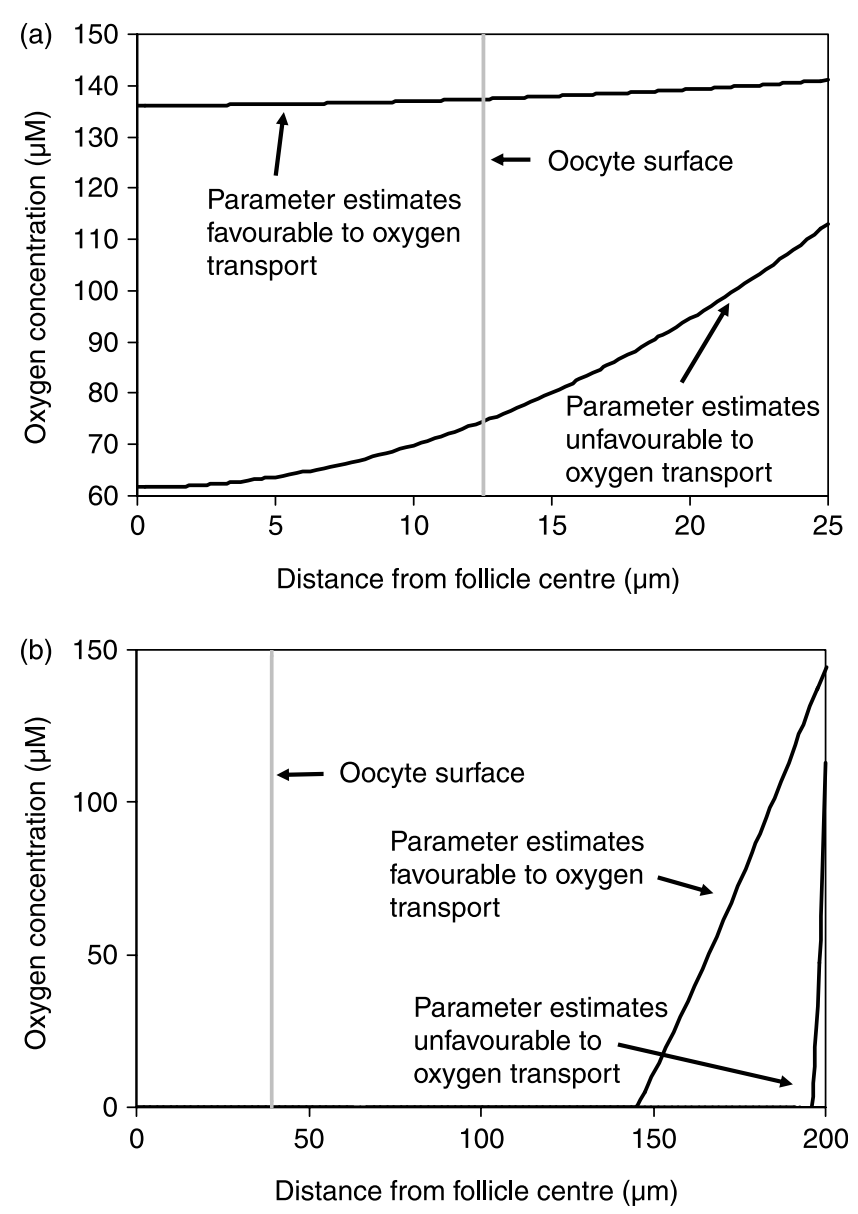

Figure 2 Oxygen concentration profiles in (a) small and (b) large preantral follicles, when fluid voidage is not considered using parameter values favourable $\left(C_{\mathrm{o}}=0.141 \mathrm{mM}, R_{\mathrm{g}}=0.0233 \mathrm{mM} / \mathrm{s}\right.$, $\left.D_{\text {eff }}=5 \times 10^{-10} \mathrm{~m}^{2} / \mathrm{s}\right)$ and unfavourable $\left(C_{\mathrm{o}}=0.113 \mathrm{mM}, R_{\mathrm{g}}=\right.$ $0.0493 \mathrm{mM} / \mathrm{s}, D_{\text {eff }}=1 \times 10^{-10} \mathrm{~m}^{2} / \mathrm{s}$ ) to oxygen transport. Depicted location of oocyte surfaces are those for human oocytes in small and large preantral follicles.

When voidage is not considered, these ranges are $0.113-0.141 \mathrm{mM}\left(C_{\mathrm{o}}\right), 0.0233-0.0493 \mathrm{mM} / \mathrm{s}\left(R_{\mathrm{g}}\right)$ and $1-5 \times 10^{-10} \mathrm{~m}^{2} / \mathrm{s}\left(D_{\text {eff }}\right)$. Parameter estimates unfavourable to oxygen transport are simply the reverse of the combination given for favourable estimates.

The results show that in both cases, oxygen reaches the area occupied by the oocyte. Figure $2 b$ shows the equivalent relationship for a large preantral follicle. The results show that oxygen does not reach the area occupied by the oocyte if fluid voidage is not considered.

Figure 3 shows the critical follicle radius of a preantral follicle at and beyond which the concentration of oxygen will be zero at the oocyte surface (calculated as a function of fluid voidage using Eq. (3)). Calculations have been carried out using parameter estimates both favourable and unfavourable to oxygen transport, and an oocyte radius of $40 \mu \mathrm{m}$ (the radius of the human oocyte in a large preantral follicle). Favourable and unfavourable parameter estimates are as defined above, except 


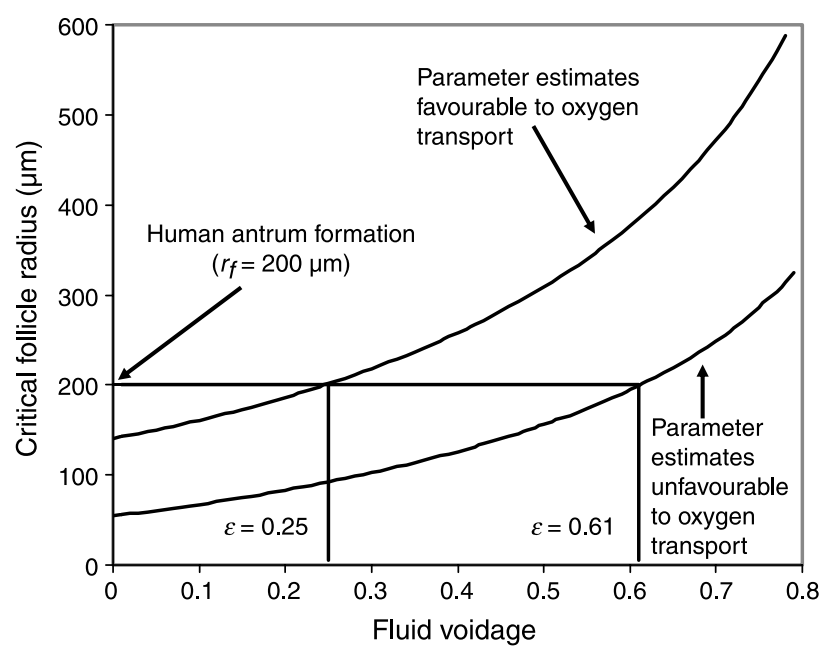

Figure 3 Critical follicle radius beyond which no oxygen reaches the oocyte surface as a function of fluid voidage. Calculations performed using the radius of a human oocyte in a large preantral follicle $\left(r_{\mathrm{o}}=\right.$ $40 \mu \mathrm{m})$. Favourable and unfavourable parameter estimates are as given in the caption of Fig. 2, except that upon the consideration of fluid voidage, $D_{\text {eff }}$ is calculated using Eq. (7) at a given fluid voidage using favourable $\left(D_{\mathrm{g}}=5 \times 10^{-10} \mathrm{~m}^{2} / \mathrm{s}\right.$ and $\left.D_{\mathrm{a}}=2.9 \times 10^{-9} \mathrm{~m}^{2} / \mathrm{s}\right)$ and unfavourable $\left(D_{\mathrm{g}}=1 \times 10^{-10} \mathrm{~m}^{2} / \mathrm{s}\right.$ and $\left.D_{\mathrm{a}}=2.3 \times 10^{-9} \mathrm{~m}^{2} / \mathrm{s}\right)$ estimates of $D_{\mathrm{g}}$ and $D_{\mathrm{a}}$.

that upon the inclusion of fluid voidage, $D_{\text {eff }}$ was calculated according to Eq. (7) using high values of $D_{\mathrm{g}}$ and $D_{\mathrm{a}}\left(5 \times 10^{-10} \mathrm{~m}^{2} / \mathrm{s}\right.$ and $2.9 \times 10^{-9} \mathrm{~m}^{2} / \mathrm{s}$ respectively) for favourable conditions and low values of these parameters $\left(1 \times 10^{-10} \mathrm{~m}^{2} / \mathrm{s}\right.$ and $2.3 \times 10^{-9} \mathrm{~m}^{2} / \mathrm{s}$ respectively) for unfavourable conditions.

The results show that for a large human preantral follicle $\left(r_{\mathrm{f}}=200 \mu \mathrm{m}\right)$, oxygen can reach the surface of the oocyte, provided that the fluid voidage is $>0.25$ if favourable model parameter estimates are used, or $>0.61$ if parameter estimates unfavourable for oxygen transport are used.

Figure 4 shows the oxygen concentration profiles in follicles with various antrum sizes at constant granulosa layer volume (calculated using Eqs (4) and (5)). The results show that as the size of the antrum increases, the size of the follicle increases and the thickness of the granulosa layer decreases. The follicle becomes increasingly oxygenated, with oxygen breaking through the granulosa layer at larger antrum sizes. Subsequent increase in antrum size results in a reduced drop in oxygen concentration across the granulosa layer and an increased oxygen concentration in the antrum.

By solving Eq. (6) for $r_{\mathrm{a}}$ such that the oxygen concentration is zero at the granulosa/antrum interface, the increase in granulosa layer volume and antral fluid volume as the size of the follicle increases could be predicted. This prediction represents what will be expected if antrum formation and growth are in response to oxygen transport limitations in the follicle (specifically in response to anoxia of the innermost granulosa cells).

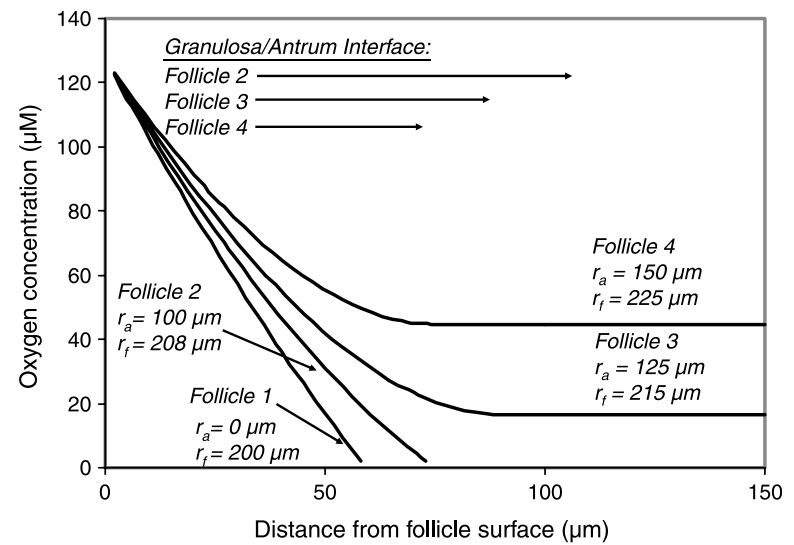

Figure 4 Comparison of oxygen concentration profiles in follicles with various antrum sizes at constant granulosa layer volume (parameters at nominal values).

In Fig. 5, this result is compared with observed human granulosa layer volumes and antral fluid volumes as a function of follicle size, and it demonstrates that the observed pattern of human follicle development is consistent with that predicted from the consideration of oxygen transport limitations. The agreement between the predictions and data appears to be better for large follicles compared with small ones. One possible explanation for this is that small errors in the measurement of parameters such as follicle diameter will have a much more visible effect on this comparison for small follicles.

The human data in Fig. 5 have been adapted from results reported by McNatty (1981). The original data presented granulosa cell numbers per follicle rather than granulosa layer volume. In Fig. 5, these data have been converted to granulosa layer volume $\left(V_{\mathrm{g}}\right)$ by assuming

$V_{\mathrm{g}}=\frac{n V_{\text {cell }}}{(1-\varepsilon)}$

where

$n$ is the number of granulosa cells per follicle $V_{\text {cell }}$ is the volume of a single granulosa cell.

The volume of a single human granulosa cell has been reported as $1140 \pm 200 \mu \mathrm{m}^{3}$ /cell (Dhar et al. 1996), and this value was used in the calculations of Fig. 5. The voidage level used to calculate $V_{\mathrm{g}}$ was the same as that used in the model calculations $(\varepsilon=0.3)$.

If antrum formation is in response to oxygen transport limitations, Eq. (3) can be used to estimate the radius of the follicle at which the antrum will form, given the oocyte radius, the granulosa cell oxygen consumption rate and the fluid voidage of the granulosa layer.

Using the ranges of oocyte radii in Table $2(32-54 \mu \mathrm{m})$, a fluid voidage ranging from 0.06 to 0.6 and parameter estimates favourable and unfavourable to oxygen transport, Eq. (3) predicts that for the mammalian species 


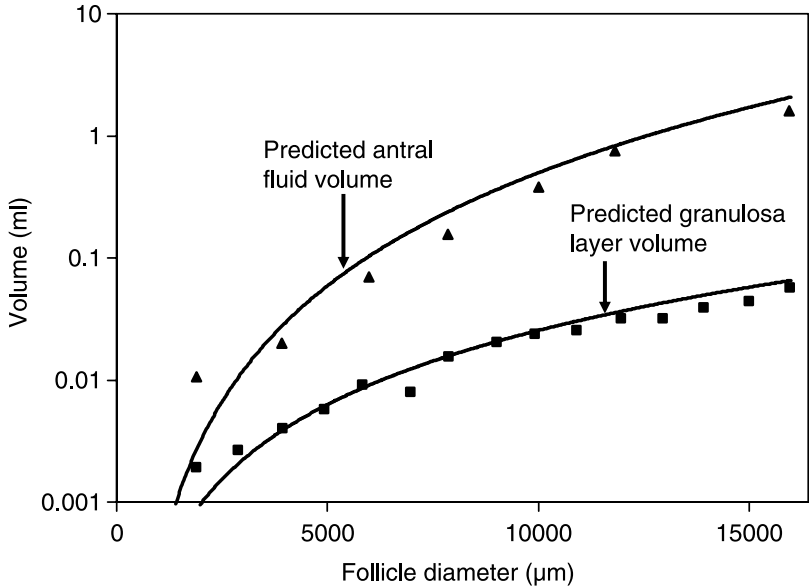

Figure 5 A comparison of predicted increase in antral and granulosa layer volume for an oxygen mass transport-limited follicle with human data. $\boldsymbol{\Lambda}$, Antral fluid volume data; $\boldsymbol{\square}$, granulosa layer volume. Data for both $\boldsymbol{\Delta}$ and $\boldsymbol{\square}$ adapted from McNatty (1981). Note that volumes are expressed on a log scale. Parameters at nominal values (i.e. predictions do not represent a best fit).

in Table 2, antrum formation will occur between the follicle radii of $\sim 60-380 \mu \mathrm{m}$. The actual observed range for the species in Table 2 is within this range and is 100$300 \mu \mathrm{m}$.

Since the radius of the follicle at which the antrum forms is known for the species in Table 2, Eq. (3) can be alternatively used to calculate the fluid voidage of the granulosa layer at antrum formation for each species. This has been done for each species in Table 2 using the nominal parameter estimate values and gives a range of $0.09 \leq \varepsilon \leq 0.65$.

Predictions of the type shown in Fig. 5 can also be expressed by plotting the ratio of antral fluid volume to total follicle volume $\left(V_{\mathrm{a}} / V_{\mathrm{f}}\right)$ as a function of follicle size. This ratio has been measured for sheep by Turnbull et al. (1977). Figure 6 shows solutions of Eq. (6) used to calculate this ratio at nominal parameter estimate values and a fluid voidage of 0.3 (as estimated for sheep in Table 2). The results are compared with the data of Turnbull et al. (1977), and they show that the observed pattern of follicular growth is once again consistent with what is expected if follicle growth is in response to oxygen transport limitations. Figure 6 also shows that the initial increase in antral volume is rapid relative to total follicle volume before becoming relatively constant.

\section{Discussion}

The results of Fig. 2 a show that oxygen can easily reach the area occupied by the oocyte in the small preantral follicle. As the follicle grows, the granulosa layer thickens and oxygen transport becomes more difficult. This occurs because as the follicle grows the surface area of oxygen supply increases as a function of $r_{f}^{2}$, but the volume of the oxygen-consuming

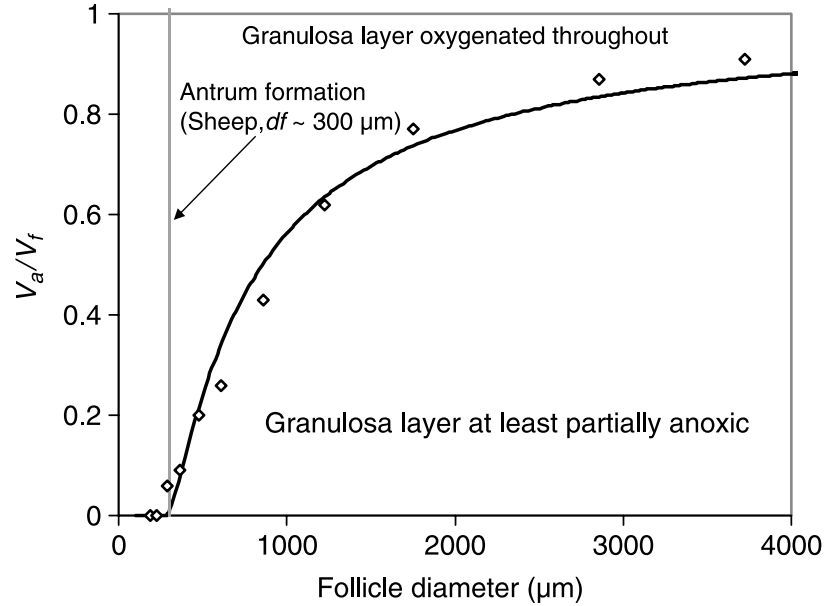

Figure 6 Ratio of antral fluid volume to total follicle volume $\left(V_{\mathrm{a}} / V_{\mathrm{f}}\right)$ required to oxygenate the granulosa layer throughout as a function of follicle size. $\diamond$, sheep data from Turnbull et al. (1977). Calculations performed using fluid voidage of 0.30 as estimated for Sheep (Table 2). Other parameters at nominal values (i.e. predictions do not represent a best fit).

granulosa layer increases as a function of $r_{\mathrm{f}}^{3}$. Hence, the demand outweighs the supply and the follicle becomes increasingly hypoxic from its core outwards. This is reflected in the results of Fig. $2 b$, which shows that oxygen does not reach the area occupied by the oocyte in the large preantral follicle. This result is consistent with the conclusions of Gosden \& Byatt-Smith (1986).

However, the results of Fig. 2 assume that the granulosa layer is a purely cellular structure. This assumption is flawed, as the granulosa layer is composed of both cells and interstitial fluid, similar to all biological tissue. Based on the fact that the granulosa layer is composed of both cells and fluid, Fig. 3 demonstrates that oxygen can reach the area occupied by the oocyte in the large preantral follicle if the fluid voidage is $>0.25$, which is certainly feasible for typical biological tissue.

The inclusion of fluid voidage in the model represents spaces where no oxygen is consumed. This further facilitates oxygen transport, as increasing fluid voidage represents a way in which the follicle can maintain a balance between oxygen supply and demand. The fluid voids also make oxygen transport less hindered as the effective diffusivity of the granulosa layer increases with increasing fluid voidage. As the fluid voidage increases, the diffusivity in the granulosa layer will approach that of the follicular fluid, which is higher than the diffusivity of oxygen through cells.

The prediction that oxygen can reach the oocyte in the large preantral follicle is in contrast to the predictions of both Fig. $2 b$ and Gosden \& Byatt-Smith (1986). This result also suggests that the metabolism of the early oocyte need not be completely anaerobic, a result that can be inferred from the work of Clark et al. (2006). 
Despite this, Fig. 3 also shows that using parameter estimates unfavourable to oxygen transport, the large human preantral follicle will require a fluid void fraction $>0.61$ if oxygen is to reach the oocyte surface. Fluid voidage as high as 0.6 has been observed in tumour tissue. The morphological and biophysical similarities between ovarian follicles and tumours have been noted (Neeman et al. 1997), and hence a fluid voidage of 0.61 in the ovarian follicle is not unfeasible. Though feasible, such a high fluid voidage is considered to be approaching the limits of what appears to be structurally physiologically possible.

Hence, whilst it is certainly likely that oxygen can reach the oocyte in larger preantral follicles, it can also be stated that, based on the results of Fig. 3, at any given fluid voidage level, a given follicle will eventually reach a size beyond which it cannot grow without the oocyte becoming starved of oxygen. Hirshfield (1991) speculated that as the granulosa layer becomes increasingly thick in the growing follicle, the innermost granulosa cells may encounter a metabolic roadblock, being simply too far from the vascular supply to obtain an adequate supply of oxygen. The predictions reported in this work lend support to this hypothesis.

During the early antral phase, follicles undergo a major structural modification in the formation of the antrum. Figure 4 shows that the formation and growth of the antrum result in an increase in the size of the follicle, thinning of the granulosa layer and a subsequent increase in the oxygenation of the follicle. This occurs because as the size of the follicle increases, the surface area of supply increases. However, the results presented in Fig. 4 assume constant granulosa layer volume. In real follicles, total follicle volume, antral fluid volume and granulosa layer volume all increase simultaneously as the follicle grows. Therefore, the formation of the antrum will only facilitate oxygenation of the granulosa layer, if it occupies at least a certain volume at any given follicle volume. This occurs once again because as the follicle grows, the surface area of oxygen supply increases as a function $r_{f}^{2}$ and the follicle can therefore support a greater volume of granulosa cells. However, as the increase in granulosa layer volume is a function of $r_{\mathrm{f}}^{3}, \mathrm{a}$ balance between oxygen supply and demand can only be achieved if the granulosa layer thins (though it still contains a greater volume as the follicle size has increased). Therefore, as the follicle becomes large, the radius of the antrum will tend toward the radius of the follicle. This process is observed practically in large follicles of some mammalian species that have very thin granulosa layers.

Figure 5 shows the predicted granulosa layer volume and fluid volumes required to achieve an oxygenated granulosa layer at a given follicle size (predictions represent the case where oxygen concentration only just falls to zero at the granulosa/antrum interface). The comparison of these predictions with the data for human follicles shows that real follicle growth is consistent with the pattern expected, if antrum formation and subsequent volume increase are mechanisms for overcoming oxygen transport limitations. This pattern of growth is consistent with that observed in other mammals (Turnbull et al. 1977, Driancourt 1979). It should be noted that Fig. 5 is not an attempted best fit. It simply represents a comparison between model predictions at nominal parameter estimates with the available data (the same applies to Fig. 6).

Hirshfield (1991) has further suggested that the 'metabolic roadblock', which may be encountered by follicles, could be a major reason for the observed atresia of so many follicles in the early antral stage, and that follicles would not be able to proceed beyond the early antral stage unless they acquired some new metabolic or structural characteristics, which enabled them to circumvent diffusion limitations. It was also suggested that higher than baseline concentrations of follicle stimulating hormone (FSH) during this period of development may somehow assist in enabling the follicle to achieve these characteristics. It is suggested here that the formation of the antrum may be the structural characteristic that allows diffusion limitations to be avoided by allowing the growing follicle and granulosa cell numbers to maintain a balance between oxygen demand and supply. If the further speculation of Hirshfield (1991) is in keeping with this suggestion, then it might be possible that the higher than baseline concentrations of FSH during this period of development may be related to antrum formation. Indeed, $\mathrm{FSH}$ has been linked to the formation of the antrum and antrum-like reorganisation of the granulosa cells (Gore-Langton \& Daniel 1990, Gutierrez et al. 2000).

Based on the assumption that antrum formation is a response to oxygen transport limitations in the preantral follicle, Eq. (3) predicts that antrum formation must occur between the follicle radii of $60-380 \mu \mathrm{m}$. The actual observed range of $100-300 \mu \mathrm{m}$ falls within this range and suggests that within the variability of the parameter estimates available, the formation of the antrum may be a response to oxygen transport limitations. To investigate this hypothesis more thoroughly, one would require species-specific data on fluid voidage of the granulosa layer, the oxygen consumption rates of the granulosa and the oxygen concentrations at the follicle surface. In fact, knowledge of all parameters as a function of follicle size will improve the predictions of the model presented here. For example, the predictions of Fig. 5 are based on a constant single granulosa cell volume $\left(V_{\text {cell }}\right)$. This may be one reason why the predictions of Fig. 5 appear to show greater deviation from the granulosa layer volume data at small follicle sizes.

More detailed knowledge of parameter estimates may greatly increase the utility of the model in formulating 
and experimental testing of hypotheses such as the possibility that antrum formation is related to oxygen transport limitations.

Information describing how fluid voidage of the granulosa layer changes as the follicle grows from the small preantral through to the antral stages would be particularly informative. The predicted values of fluid voidage at antrum formation in the granulosa layer for various species in Table 2 suggest that this parameter may be quite species specific. The values range from the lower limit found in biological tissue to the upper limit found in some tumour tissue (note that although the calculations of Fig. 5 were performed at a nominal fluid voidage of 0.3 , it has been confirmed that changing this value to 0.46 as predicted for humans in Table 2 does not significantly affect this graph). Of course, these calculations assume a constant granulosa cell oxygen consumption rate for all species. This assumption may be flawed, and it may be equally likely that fluid voidage is fairly constant between species, with the granulosa cell oxygen consumption rates varying relatively widely. Once again, experimental investigation is required to shed light on these issues.

The granulosa cell oxygen consumption rate used in this work is for sheep. Therefore, the fluid voidage prediction of 0.30 for sheep can be considered the most reliable estimate and is the same as the nominal value used in this work. Using this value, Fig. 6 expresses predictions equivalent to those of Fig. 5 in a different form. The results are compared with the data collected from sheep follicles by Turnbull et al. (1977). Once again, the results show that observed follicle growth is consistent with that predicted if it is in response to oxygen transport limitations. In order to achieve a fully oxygenated granulosa layer, the antral fluid to total follicle volume ratio must be at or above the predicted line at any given follicle volume. Below the line, the granulosa layer will be at least partially anoxic, increasingly so the lower the ratio. $V_{\mathrm{a}} / V_{\mathrm{f}}$ ratios above the predicted line will allow oxygen to enter the antrum, across which the oxygen concentration will be constant. The higher the ratio, the higher the oxygen concentration in the antral fluid at any given follicle size. It should be noted that Fig. 6 shows that $V_{\mathrm{a}} / V_{\mathrm{f}}$ tends towards 1 as follicles become larger, which is consistent with previously discussed geometrical considerations.

Although the mathematical model of Gosden \& Byatt-Smith (1986) did not extend to include antrum formation, the authors did speculate that the formation of the antrum in which there is negligible oxygen consumption and greater oxygen diffusivity may be a mechanism for coping with the problem of oxygenating an avascular structure. The results presented here lend support to this hypothesis.
Based on the model of Gosden \& Byatt-Smith (1986), Van Blerkom (1998) speculated that intrafollicular oxygen should rise with antrum formation. This work suggests that this will likely be the case, but only if follicle and antrum growth achieve a certain ratio at any given follicle size.

Gore-Langton \& Daniel (1990) suggest that antrum formation may satisfy the need of the rapidly growing follicle to minimise the barrier to passive diffusion of gases, nutrients and/or blood-derived hormonal substances, while permitting the continued proliferation of granulosa and follicular expansion. The predictions given here are consistent with this explanation in terms of oxygen transport. It should be noted that although the predictions presented in this work demonstrate that follicle development is consistent with oxygen transport limitations, it is possible that the follicle expands in order to provide some other unrelated functional advantage, which, as a side effect, results in follicle oxygenation.

Figure 6 also demonstrates that at small follicle volumes, the $V_{\mathrm{a}} / V_{\mathrm{f}}$ ratio is very sensitive to small changes in follicle size. Therefore, at this early antral stage, it may be most difficult for the follicle to achieve the minimal volume ratio required to ensure it is not oxygen starved. If oxygen depletion of the granulosa layer is related to follicle atresia as suggested by Hirshfield (1991), then this difficulty may be a reason for the observed atresia of many follicles in the early antral phase.

If the $V_{\mathrm{a}} / V_{\mathrm{f}}$ ratio is related to follicle atresia and/or the nutrient supply of the follicle, then it may be speculated that this ratio could also be related to oocyte competence. Experimental investigation of this hypothesis is recommended. This may be most easily achieved for large follicles, as Fig. 6 shows that this ratio becomes relatively insensitive to follicle size as the follicle grows. Follicles with abnormally low values of this ratio may represent follicles starved of oxygen and other vital substances. It should also be noted that this work assumes a completely vascularised follicle. Oxygenation of the granulosa layer will also be dependent on the degree of vascularisation. Therefore, the interaction of $V_{a} / V_{f}$ and follicle vascularisation also needs to be considered further. The impact of variable follicle vascularisation on the preantral follicle also needs to be determined.

In conclusion, mathematical modelling of oxygen transport in the preantral and antral follicles was investigated. The results show that oxygen can reach the oocyte, even in large preantral follicles. However, in the absence of antrum formation, the preantral follicle will eventually reach a size beyond which it cannot grow without the oxygen levels seen by the oocyte becoming very low. The formation of the fluid antrum represents a mechanism that may allow the follicle to overcome this limitation. These results have important implications in the understanding of follicle 
growth and atresia. The same is true of the general approach of modelling mass transport in the follicle, which can be used to assist in the formulation and testing of new hypotheses related to follicle development.

\section{Acknowledgements}

The work reported here was funded as part of the contract C10X0204, 'Advanced Tools for the Problem of Infertility in Women', awarded to AgResearch Ltd by the New Zealand Foundation for Research Science and Technology. The authors declare that there is no conflict of interest that would prejudice the impartiality of this scientific work.

\section{References}

Battino R, Rettich TR \& Tominaga T 1983 The solubility of oxygen and ozone in liquids. Journal of Physical Chemical Reference Data 12 163-178.

Bhal P, Pugh N, Chui D, Gregory L, Walker S \& Shaw R 1999 The use of transvaginal power doppler ultrasonography to evaluate the relationship between perifollicular vascularity and outcome in in vitro fertilization treatment cycles. Human Reproduction $\mathbf{1 4}$ 939-945.

Van Blerkom J 1998 Epigenetic influences on oocyte developmental competence: perifollicular vascularity and intrafollicular oxygen. Journal of Assisted Reproduction and Genetics 15 226-234.

Van Blerkom J, Antczak M \& Schrader R 1997 The development potential of the human oocyte is related to the dissolved oxygen content of follicular fluid: association with vascular endothelial growth factor levels and perifollicular blood flow characteristics. Human Reproduction 12 1047-1055.

Chui D, Pugh N, Walker S \& Shaw R 1997 Follicular vascularity - the predictive value of transvaginal Doppler ultrasonography in an in vitro fertilization programme: a preliminary study. Human Reproduction 12 191-196.

Clark AR, Stokes YM, Lane M \& Thompson JG 2006 Mathematical modelling of oxygen concentration in bovine and murine cumulusoocyte complexes. Reproduction 131 999-1006.

Dhar A, Dockery P, Turner K, Lenton EA \& Cooke ID 1996 The human ovarian granulosa cell: a stereological approach. Journal of Anatomy 188 671-676.

Driancourt MA 1979 Follicular kinetics in the mare ovary. Annales de Biologie Animale Biochimie Biophysique 19 1443-1453.

Dutta A \& Popel AS 1995 A theoretical analysis of intracellular oxygen diffusion. Journal of Theoretical Biology 176 433-445.

Evans NTS, Naylor PFD \& Quinton TH 1981 The diffusion coefficient of oxygen in respiring kidney and tumour tissue. Respiration Physiology 43 179-188.

Fischer tyB, Kunzel W, Kleinstein J \& Gips H 1992 Oxygen tension in follicular fluid falls with follicle maturation. European Journal of Obstetrics Gynaecology and Reproductive Biology 43 39-43.

Fournier RL 1998 Oxygen transport in biological systems. In Basic Transport Phenomena in Biomedical Engineering, pp 87-114. Philadelphia: Taylor and Francis.

Gore-Langton RE \& Daniel SAJ 1990 Follicle-stimulating hormone and estradiol regulate antrum-like reorganisation of granulosa cells in rat preantral follicle cultures. Biology of Reproduction 43 65-72.

Gosden RG \& Byatt-Smith JG 1986 Oxygen concentration gradient across the ovarian follicular epithelium: model, predictions and implications. Human Reproduction 1 65-68.
Gutierrez GC, Ralph JH, Telfer EE, Wilmut I \& Webb R 2000 Growth and formation of bovine preantral follicles in long-term culture in vitro. Biology of Reproduction 62 1322-1328.

Hirshfield AN 1991 Development of follicles in the mammalian ovary. International Review of Cytology 124 43-101.

Huey S, Abuhamad A, Barroso G, Hsu M-I, Kolm P, Mayer J \& Oehninger S 1999 Perifollicular blood flow Doppler indices, but not $\mathrm{pO}_{2}, \mathrm{pCO}_{2}$, or $\mathrm{pH}$, predict oocyte developmental competence in in vitro fertilization. Fertility and Sterility $\mathbf{7 2}$ 707-712.

Hunter RHF, Einer-Jenson N \& Greve T 2006 Presence and significance of temperature gradients among different ovarian tissues. Microscopy Research and Technique 69 501-507.

Jones DP 1984 Effect of mitochondrial clustering on $\mathrm{O}_{2}$ supply in hepatocytes. American Journal of Physiology 247 C83-C89.

Jones DP \& Kennedy FG 1986 Analysis of intracellular oxygenation of isolated adult cardiac myocytes. American Journal of Physiology 250 C384-C390.

Kim KH, Oh DS, Jeong JH, Shin BS, Joo BS \& Lee KS 2004 Follicular blood flow is a better predictor of the outcome of in vitro fertilization-embryo transfer than follicular fluid vascular endothelial growth factor and nitric oxide concentrations. Fertility and Sterility 82 586-592.

Kumar A, Solanki SK, Jindal SK, Tripathi VN \& Jain GC 1997 Oocyte retrieval and histological studies of follicular population in buffalo ovaries. Animal Reproduction Science 47 189-195.

Lango T, Morland T \& Brubakk AO 1996 Diffusion coefficients and solubility coefficients for gases in biological fluids and tissues: a review. Undersea and Hyperbaric Medicine 23 247-272.

McNatty KP 1978 Follicular fluid. In The Vertebrate Ovary Comparative Biology and Evolution, pp 215-259. Ed. RE Jones. New York: Plenum Press.

McNatty KP 1981 Hormonal correlates of follicular development in the human ovary. Australian Journal of Biological Science 34 249-268.

Mossman HW \& Duke KL 1973 General microscopic structure of the mammalian ovary. In Comparative Morphology of the Mammalian Ovary, pp 34-52. Wisconsin: The University of Wisconsin Press.

Neeman M, Abramovitch R, Schiffenbaur YS \& Tempel C 1997 Regulation of angiogenesis by hypoxic stress: from solid tumours to the ovarian follicle. International Journal of Experimental Pathology 78 57-70.

Nicholson C 2001 Diffusion and related transport mechanisms in brain tissue. Reports on Progress in Physics 64 815-884.

Parkes AS 1931 The reproductive processes of certain mammals. II. The size of the graafian follicle at ovulation. Proceedings of the Royal Society of London. Series B, Containing Papers of a Biological Character 109 185-196.

Peters H \& McNatty KP 1980 Morphology of the ovary. In The Ovarya Correlation of Structure and Function in Mammals. London: Granada Publishing.

Redding GP 2007 Oxygen and the ovarian follicle. Thesis for the Degree of Doctor of Philosophy, Massey University, Palmerston North, New Zealand.

Redding GP, Bronlund JE \& Hart AL 2006 Palmerston North, New Zealand. The effects of IVF aspiration on the temperature, dissolved oxygen levels, and $\mathrm{pH}$ of follicular fluid. Journal of Assisted Reproduction and Genetics 23 37-40.

Riley MR, Muzzio FJ, Buettner HM \& Reyes SC 1994 Monte carlo calculation of effective diffusivities in two- and three- dimensional heterogeneous materials of variable structure. American Journal of Physiology 49 3500-3503.

Riley MR, Muzzio FJ, Buettner HM \& Reyes SC 1995 Diffusion in heterogeneous media: application to immobilized cell systems. AlChE Journal 41 691-700.

Riley MR, Muzzio FJ, Buettner HM \& Reyes SC 1996 A simple correlation for predicting effective diffusivities in immobilized cell systems. Biotechnology and Bioengineering 49 223-227. 
Rumsey WL, Schlosser C, Nuutinen EM, Robiolio M \& Wilson DF 1990 Cellular energetics and the oxygen dependence of respiration in cardiac myocytes isolated from adult rat. Journal of Biological Chemistry 265 15392-15399.

Tai RC \& Chang H 1974 Oxygen transport in heterogeneous tissue. Journal of Theoretical Biology 43 265-276.

Truskey GA, Yuan F \& Katz DF 2004a Transport of gases between blood and tissues. In Transport Phenomena in Biological Systems, pp 609-638. New Jersey: Pearson Prentice Hall.

Truskey GA, Yuan F \& Katz DF 2004b Transport in porous media. In Transport Phenomena in Biological Systems, pp 387-426. New Jersey: Pearson Prentice Hall.
Turnbull KE, Braden AWH \& Mattner PE 1977 The pattern of follicular growth and atresia in the ovine ovary. Australian Journal of Biological Science 30 229-241.

Received 28 August 2006

First decision 31 October 2006

Revised manuscript received 13 February 2007

Accepted 22 February 2007 